\title{
CORRESPONDENCE
}

\section{Creationists persist}

SIR - No doubt the opponents of evolution are delighted with the fireworks of disagreement that are now being displayed on this subject by biologists who write to Nature. Indeed, the critics of Copernicus took heart 400 years ago because scientists could not agree among themselves. However, it is not likely that the scientific process of argument betokens a swing to creationism.

During the Sacramento trial, 2-6 March, the creationists roared as gently as any sucking dove. They said, in the courtroom, that they were not seeking equal time for the teaching of creationism with evolution. In the corridors, talking to reporters, it was a different story. Their veteran leader, Mrs Nell Segraves, said: "We want 50 per cent of the tax dollar used for education to our point of view. We have a lot to undo. Creation/evolution is only the beginning.'

The head of the Institute for Creation Research, San Diego, Henry Morris, PhD (Hydraulic Engineering), does not mince matters when he is writing for an audience of believers. He has said that "It is high time that Christians face the fact that the so-called geologic ages are essentially synonymous with the evolutionary theory of origins. The latter, in turn, is, at its ultimate roots, the anti-God conspiracy of Satan himself." He also says the fractures and scars of the Moon and Mars reflect a fight between good and bad angels.

However, the argument used for persuading school boards and legislatures is that "creation science" is a credible variant of conventional science, and deserves equal time. A creationist textbook has anticipated and countered Ashley Montagu's plea (Nature 23 April, p.623) that "perhaps the most remarkable and obvious [example of evolution in process] is the wellknown case of industrial melanism in moths", Not so, say the creationists, "The moths are just the same as they were before the Industrial Revolution, and they are not becoming anything different ... Darwin devoted his life in attempting to make it seem reasonable that all forms of life on Earth evolved from one or a few simple forms; this is a very different matter from birds selecting dark or light moths according to the type they can see more readily on a certain

background"'. This argument is strengthened by recent observations that the black morphs are now disappearing because soot is disappearing from trees in the formerly smoky and unkind Midlands.

Creationism is on the march in Oregon, Florida, and Michigan. Governor Frank White signed the Arkansas Bill on 19 March requiring the "balanced treatment"' of "creation-science" and evolution in public schools, and admitted afterwards that he had not read all of it. However, on 29 March he told a church congregation that creationscience "is a theory supported by documentation, and evolution-science is the same".

The "equal time for nonsense" position is not one that favours science; science is governed by merit, not fairness. As pointed out by Weber, the position that has the best evidence, has withstood prolonged criticism, and has the mass support from knowledgeable workers in the field, is the position that should be given the emphasis in education. In science, one theory is not just as good as another.

THOMAS H. JUKES

University of California,

Berkeley, USA

\section{Theory upon theory}

SIR - The author of the article "How true is the theory of evolution"' (Nature 12 March, p.75) seemed to misapprehend Popper's refutation principle. He referred not only in the title to the "truth" of a theory but in the article also, where he compounded the error by writing about "proving" theories. Truth and Proof are precisely what Popper's refutation principle does not establish.

It is also unnecessarily narrow to apply Popper's demarcation principle as the exclusive arbitrator in a dispute over the scientific content of a theory. There is no known test or property that demonstrates unequivocally that a theory is scientific or otherwise (see, for example, The Structure of Scientific Theory, ed. F. Suppe, 1977). Popper's demarcation principle is not exceptional in this respect; it is probably an analysis most suitably used to explore the scientific content of the theories of physics rather than evolutionary theories, the latter have a historical component the former lack.

Historical theory is often formally different from scientific theory as defined by Popper, as the former can sometimes be confirmed by a finite number of observations. They are confirmed or refuted when all possible observations have been made. In this type of theory, refutation has no logical priority over confirmation - the state of affairs Popper claims for the theories he labels as scientific.

An example of the confirmation/refutation symmetry in historical theory may be found in the theory of evolution, where the gaps in the fossil record are explained sometimes as undiscovered transitional forms. This is theoretically a confirmable historical theory, though in practice the examination of every piece of the Earth's sedimentary rock would be an impossible task. In reality, this theory becomes irrefutable and therefore not scientific according to Popper, unless we interpret his "falsifiable in principle" to mean theoretically testable even if not testable in practice. Popper seems to interpret it thus, as in the New Scientist (21 August 1980) he claims historical theories are scientific, but this seems to upset his claim for the priority of refutability over confirmation as a property of scientific theories. On the other hand, should the interpretation be that the explanation of the gaps as transitional forms was in practice irrefutable, it is difficult to accept that finding transitional forms that fit the gaps is in no way a scientific activity.

I would also like to draw to the attention of the author of the article in Nature a conclusion of Feyerabend, for example, who states that "relativity theory does not modify Newtonian mechanics, it displaces the theory altogether". The displacement of one major theory by another, according to him, occurs because the two theories represent mutually exclusive universes of discourse and therefore do not have a common language. In this instance, because the two theories embrace incompatible concepts of motion, Newtonian mechanics and the theory of relativity therefore on

Feyerabend's analysis do not have an analogous relationship to Lamarckism and neo-Darwinism. The author's conclusion that Lamarckism would modify neo-Darwinism was correct, but the analogy chosen was probably inappropriate.

BARRIE PEARSON Winfrith, Dorchester, UK

\section{Use the library}

SIR - The recent letter from Andrew Brooks ${ }^{1}$ indicates problems which are encountered by everyone engaged in research. As a Librarian/Information Officer in a small research institute, I often find that the information aspect of research work is approached the wrong way round. The laboratory work is done and a paper almost written before the library is consulted for relevant references. Senior research staff can be particularly guilty, relying strongly on the "old boy" network.

The information explosion of the past 15 years has greatly complicated the task of obtaining relevant information and sophisticated systems have been developed to make the job easier. Chemical Abstracts is perhaps the best known information retrieval tool in the sciences. This includes about half a million abstracts per year and anyone not knowing how to use it will have difficulty in retrieving any relevant information.

Computerized data bases abound and a directory has been published ${ }^{2}$. Chemical Abstracts can also be searched on-line ${ }^{3}$.

Training in how to obtain information from published sources is surely now essential. I feel it is time for a compulsory, assessed course in information retrieval for undergraduates to be introduced along with other core subject courses.

International Tin Research Institute, Gill Croft Greenford, Mddx, UK

1. Brooks, A. Nature 291, 7 (1981).

2. Hall, J.L. On-line Bibliographic Data Bases (Aslib, London, 1981).

3. Barker, F.H. Aslib Proc. 31, 538 (1979).

SIR - Several months to carry out a literature search! Andrew Brooks' letter (Nature 7 May, p.7) amazes me and seems to reveal a lack of initiative by him and by his library. It is part of the job of an academic librarian to explain information handling techniques, whether informally or via a specialist course. In addition, most of us have access to computerized information sources and use them routinely to undertake literature searching for teaching and research staff. Surely a first task for any new researcher (or, indeed, lccturer) is to find out what services the library offers, just as he will investigate available computing facilities. Did Mr Brooks not do this? Conversely, though there are obviously difficulties in institutions with large numbers of researchers, librarians should seek out and make contact with new staff to explain their services. Nevertheless, the SRC might still usefully insist on a course of research methods, including techniques of information retrieval, as an initial part of any PhD programme. I.R. WINSHIP

Polytechnic Library,

Newcastle-upon-Tyne, UK 